\title{
Construction of Health Infrastructure Index in Haryana: An Econometric Approach
}

\author{
M. M. Goel \\ R G N I Y D, Govt. of India, Sriperumbudur (Tamil Nadu) \\ Ishu Garg \\ Department of Economics, Kurukshetra University, Kurukshetra (Haryana)
}

\begin{abstract}
The provision of health infrastructure is one of the major areas of concern in Indian economy including Haryana. Health infrastructure which comprises all the resources necessary to provide health services, is proved to be essential to create health human capital. Thus, being a merit good, establishment of health infrastructure is the prime duty of the State. With this backdrop, the present study is attempted to construct health infrastructure index for the State of Haryana. On the basis of the available data taken from various issues of Statistical Abstract of Haryana, fourteen indicators of health infrastructure are considered for the period of twenty one years from 1991-92 to 201112. First of all, the collected data is analyzed by computing descriptive statistics which reveal that seven indicators of health infrastructure possess positive compound annual growth rate (CAGR) while seven others have negative CAGR and certain indicators have experienced high variations in their number over the years. Next, normalization of data is done and then by applying principal component analysis (PCA), composite index for health infrastructure is constructed in various steps including correlation matrix, KMO measure and Bartlett's test; eigenvalues of components; component loading matrix; calculation of weights for variables (indicators of health infrastructure) and finally health infrastructure index. As per index scores, ranks are given to the State for its health infrastructure for all twenty one years. It is found that health infrastructure in Haryana for the year 2004-05 have attained rank $1^{\text {st }}$ with index score 1.000, followed by 2011-12 with score 0.837 and the year 2003-04 having the value of 0.764. Between 1991-92 and 2011-12, up and downs in index scores as well as in ranks are seen. Besides, score of health infrastructure index remain up to 0.5 for eleven years while above 0.5 for ten years. However, the year 200910 can be considered quite embarrassing for which score of health infrastructure index is zero indicating availability of health infrastructure was at lowest level in this year. Fortunately, the year 2011-12 having $2^{\text {nd }}$ rank in health infrastructure index arises a ray of hope for the further promotion in the availability of health infrastructural facilities in coming years in State of Haryana. However, negative growth rates of certain indicators and low scores of health infrastructure index calls for immediate attention of Government with sufficient investments towards health infrastructure in Haryana.
\end{abstract}

Key words: Composite index, Principal component analysis, indicators of health infrastructure.

\section{INTRODUCTION}

In the age of globalization, health is one of the human rights everywhere including Haryana - a prosperous State of Indian economy. Health which refers to the state of complete physical, mental, social and spiritual wellbeing and not merely an absence of disease; received prominent place in the construction of human development index since 1990. In this context, World

Journal of Technology Management for Growing Economies Vol. 9 , No. 1 April, 2018 pp. 103-123

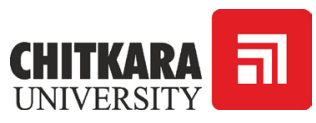

(C)2018 by Chitkara University. All Rights Reserved. 
Goel, M. M.

Garg, I.

104

Health Organization pointed out the dependency of health on the availability of better health infrastructure in terms of health institutions, medical staff, beds in medical institutions, and doctor - patient ratio, doctor - nurse ratio et cetera (Saikia and Bhattacharjee, 2011). Therefore, provision of health infrastructure, health services and related health issues are one of the prime areas of concern. Besides, role of health infrastructure in the improvement of health indicators namely life expectancy, crude birth and death rates, infant mortality rate, maternal mortality rate and eradication of all diseases, is recognized all over the world (Subba Lakshmi and Sahoo, 2013; Anand, 2014). Thus, policy makers consider the health infrastructural facilities as one of the most decisive dimension for the attainment of the social goal of 'Health for all' by the year 2020. Moreover, the health related targets of Millennium Development Goals (MDGs: 2000 - 2015) as well as of Sustainable Development Goals (SDGs: 2015 - 2030) makes the States careful towards the attainment of equity, efficiency and sufficiency in health infrastructure which can be possible by significant investments (Goel, 2011; Goel and Garg, 2016). An adequate health care infrastructure has many components such as physical facilities; laboratory, training, and other support facilities; reliable supplies of pharmaceuticals and other materials; trained staff and professional training systems; by which preventive, diagnostic, and curative care is provided (Kumar and Gupta, 2012; IZUMI Foundation, 2013).

Thus, there may be a number of indicators which form health infrastructure, and from practical stand point, it becomes difficult to identify common trends across separate indicators. For the same, economists realize on composite indices (CI) which prove helpful in analyzing those concepts which encompass multiple indicators. With the help of composite indices, the indicators defining a particular phenomenon are merged into a single score value so that clear, relevant and reliable messages can be obtained (OECD, 2008). Keeping the same in mind, the present paper is primarily concerned with constructing a composite index for health infrastructure in the State of Haryana. Specifically following objectives are worked upon:

(1) To describe health infrastructure in Haryana on its individual indicators across selected years.

(2) To construct composite index for health infrastructure, and discuss its overall methodology.

(3) To examine health infrastructure according to overall ranking based on index scores.

\section{REVIEW OF LITERATURE}

Analyzing health infrastructure, health services and health outcomes through construction of composite indices is very popular among economists and

Journal of Technology Management for Growing Economies, Volume 9, Number 1, April 2018 
researchers all over the world. Therefore, there is no dearth of literature and out of which some are reviewed as follows:

Kumari and Raman (2011) developed composite indices of education and health attainment during 1990-91 and 2007-08 for Uttar Pradesh by using Principal Component Analysis. They considered eight and thirteen indicators for the health and educational attainment respectively. They found the existence of wide disparity among Districts with respect to education and health. However, Districts having good educational attainment are found to be poor in health attainment while the Districts with well performance in health remained poor in education.

Saikia (2012) used Data Envelopment analysis (DEA) and Principal Component analysis (PCA) to analyze the regional disparity with regard to social sector in India including all States and one Union Tertiary as Delhi. On the basis of two techniques the various ranks are given to the States which explore the presence of regional inequalities in social sector development in India. However, no significant difference exists between the rankings given by DEA and PCA since the rank correlation coefficient between them is strong.

Subba Lakshmi and Sahoo (2013) constructed the health infrastructure index for the period 1980-2010 considering health inputs like number of hospitals and dispensaries, number of beds and number of doctors in government hospitals for the State of Andhra Pradesh by applying principal component analysis. Utilizing health infrastructure index, elasticity coefficients of health indicators with respect to health infrastructure were computed by using double log simple regression model. In order to calculate elasticity coefficients, they. The results revealed that the elasticity coefficients of health indicators like crude birth rate, crude death rate, infant mortality rate and life expectancy at birth with respect to health infrastructure are $-37.966,-27.816,-30.598$ and 10.282 respectively. Thus, public health facilities are crucial for meeting the basic health requirements of masses in the state.

Anand (2014) by using Principal Component Analysis computed the composite indices of health status and health services for two Indian States namely Uttar Pradesh and Bihar. The study found the existence of wide interdistrict and interregion health disparity in both States with lower disparity in Uttar Pradesh as compared to Bihar in terms of health status and relatively high disparity in health infrastructure.

Lyngdoh (2015) made an attempt to form a healthcare infrastructure index for the north eastern States for the years 2001 and 2011 with the help of Principal Component Analysis. With this health infrastructure index, the States were ranked. The study explored that Tripura attained first rank and Mizoram got second rank in health infrastructure index during 2001 as well as 2011;

Journal of Technology Management for Growing Economies, Volume 9, Number 1, April 2018
Construction

of Health

Infrastructure 
Goel, M. M.

Garg, I.

106

the index score of Arunachal Pradesh have improved in 2011 over 2001. But States of Assam and Meghalaya were found to be the poorest performers.

Motivating from this literature, the present research work is conducted to examine health infrastructure in Haryana through estimation of its composite index.

\section{METHODOLOGY}

This section highlights the collection of data, selection of time period and variables, model for composite index and statistical techniques as follows:

\section{1). Data Collection, Time Period and Selection of Variables}

For the present study, data on health infrastructure is collected from various issues of Statistical Abstract of Haryana published by Government of Haryana each year. According to the data availability, fourteen major indicators of health infrastructure are selected (table 1) with data for a period of 1991-92 to 2011-12 (table 2). These indicators are the variables for present research.

Table 1: Health Infrastructure Indicators

\begin{tabular}{|c|c|c|c|}
\hline $\begin{array}{l}\text { Infrastruc- } \\
\text { ture }\end{array}$ & $\begin{array}{c}\text { Broad } \\
\text { Ingredients }\end{array}$ & Indicators & $\begin{array}{l}\text { Abbreviations used } \\
\text { in Analysis }\end{array}$ \\
\hline \multirow{3}{*}{$\begin{array}{l}\text { Allopathic } \\
\text { Institutions }\end{array}$} & $\begin{array}{l}\text { Medical } \\
\text { Institutions }\end{array}$ & $\begin{array}{l}\text { 1. Hospitals } \\
\text { 2. Primary Health Centers } \\
\text { 3. Dispensaries } \\
\text { 4. Community Health Centers } \\
\text { 5. Sub Centers }\end{array}$ & $\begin{array}{l}\text { 1. Hos } \\
\text { 2. PHCs } \\
\text { 3. Dis } \\
\text { 4. CHCs } \\
\text { 5. SCs }\end{array}$ \\
\hline & $\begin{array}{l}\text { Medical } \\
\text { Staff }\end{array}$ & $\begin{array}{l}\text { 6. Doctors } \\
\text { 7. Nurses } \\
\text { 8. Other Staff }\end{array}$ & $\begin{array}{l}\text { 6. Doc } \\
\text { 7. Nur } \\
\text { 8. OS }\end{array}$ \\
\hline & Others & 9. Beds & 9. Beds \\
\hline \multirow{2}{*}{$\begin{array}{c}\text { AYUSH } \\
\text { Institutions }\end{array}$} & $\begin{array}{l}\text { Medical } \\
\text { Institutions }\end{array}$ & $\begin{array}{l}\text { 10. Ayurvedic Institutions } \\
\text { 11. Unani Institutions } \\
\text { 12. Homeopathic Institutions }\end{array}$ & $\begin{array}{l}\text { 10. AIs } \\
\text { 11. UIs } \\
\text { 12. HIs }\end{array}$ \\
\hline & $\begin{array}{l}\text { Medical } \\
\text { Staff }\end{array}$ & $\begin{array}{l}\text { 13. Vaidyas/ Hakims } \\
\text { 14. Dispensers/Compounders }\end{array}$ & $\begin{array}{l}\text { 13. Va/Ha } \\
\text { 14. } \mathrm{Dis} / \mathrm{Com}\end{array}$ \\
\hline
\end{tabular}

Source: Researchers' Compilation

There may be other variables also which define health infrastructure, but because of unavailability of reliable data on other indicators, these are not considered in the paper. According to the latest Statistical Abstract of Haryana, health infrastructure in Haryana is a combination of infrastructure allopathic

Journal of Technology Management for Growing Economies, Volume 9, Number 1, April 2018 
institutions as well as AYUSH (ayurvedic, unani, siddha, and homoeopathic) institutions which are operative in the State and providing their services to people. The variables can be noted from table 1 .

\section{2). Composite Index and Statistical Technique}

Composite index is the aggregation of selected variables into one score. There are a number of techniques for aggregation with or without weights. But, mostly, aggregations are done by using weights. Mathematically, Composite Index $=\sum_{\mathrm{i}=1}^{\mathrm{N}} \mathrm{W}_{\mathrm{i}} \mathrm{v}_{\mathrm{i}} / \sigma_{\mathrm{i}}$

Where, $\mathrm{w}_{\mathrm{i}}=$ weight of respective variable; $\mathrm{v}_{\mathrm{i}}=$ variable; $\sigma_{\mathrm{i}}=$ standard deviation of variable $\left(\mathrm{v}_{\mathrm{i}}\right)$ and $\mathrm{N}=$ number of variables.

In order to make the variable with unit variance, this variable is divided by its standard deviation (Fernando et al. 2012). However, from the point of view of index construction, the selection of measurement units and estimation of weights is much cumbersome.

In the present research work, Principal Component Analysis (PCA) is the foremost econometric technique used to arrive at the weights. IBM SPSS Statistics (Version 20) is utilized to apply the technique. Other major calculations are completed manually as well as by using Microsoft Excel (2013). A number of studies have applied Principal Component Analysis (PCA) for the computation of weights in index construction. In this context, OECD (2008), Nicoletti et al. (2000), Sharpe and Andrews (2012), Fernando et al. (2012), Singh and Gupta (2013), Anand (2014), Daka and Fandamu (2016) are few to mention. The procedures described by these researchers is the basis of statistical methods applied in the present paper.

\section{ANALYSES AND INTERPRETATIONS}

This section is mainly divided into three sub-sections and describes the analysis of data completed with suitable statistical techniques to arrive at the objectives.

\section{1). Health Infrastructure in Haryana across Individual Indicators}

In order to achieve the first objective table 2 provides a snapshot of collected data and descriptive statistics. It is found that since 1991-92, some of the indicators including numbers of PHCs, CHCs, SCs, doctors, ayurvedic and homoeopathic institutions and their dispensers/compounders have increased as they possess positive compound annual growth rate (CAGR). While the indicators including hospitals, dispensaries, nurses, other staff, beds, unani institutions and vaidyas/ hakims has faced negative CAGR in their number.

Journal of Technology Management for Growing Economies, Volume 9, Number 1, April 2018
Construction

of Health

Infrastructure 
Goel, M. M. Garg, I.

108
Table 2: Indicators of Health Infrastructure in Haryana during 1991-92 to 2011-12

(all figures are in numbers)

\begin{tabular}{|c|c|c|c|c|c|c|c|c|c|c|c|c|c|c|}
\hline \multirow[b]{3}{*}{ Years } & \multicolumn{9}{|c|}{ Infrastructure in Allopathic Institutions } & \multicolumn{5}{|c|}{ Infrastructure in AYUSH Institutions } \\
\hline & \multicolumn{5}{|c|}{ Medical Institutions } & \multicolumn{3}{|c|}{ Medical Staff } & & \multicolumn{3}{|c|}{ Medical Institutions } & \multicolumn{2}{|c|}{ Medical Staff } \\
\hline & $\begin{array}{c}\text { Hospi- } \\
\text { tals } \\
\text { (Hos) }\end{array}$ & PHCs & $\begin{array}{c}\text { Dispen } \\
\text { saries } \\
\text { (Dis) }\end{array}$ & CHCs & SCs & $\begin{array}{c}\text { Doctors } \\
\text { (Doc) }\end{array}$ & \begin{tabular}{|c} 
Nurses \\
(Nur)
\end{tabular} & $\begin{array}{l}\text { Other } \\
\text { Staff } \\
\text { (OS) }\end{array}$ & Beds & $\begin{array}{c}\text { Ayur- } \\
\text {-vedic } \\
\text { (AIs) }\end{array}$ & $\begin{array}{l}\text { Unani } \\
\text { (UIs) }\end{array}$ & $\begin{array}{c}\text { Ho- } \\
\text { moeo- } \\
\text { pathic } \\
\text { (HIs) }\end{array}$ & $\begin{array}{c}\text { Vaidy- } \\
\text { as } / \\
\text { Hakims } \\
(\mathrm{Va} / \mathrm{Ha})\end{array}$ & \begin{tabular}{|c} 
Dispens- \\
ers/ \\
Com- \\
pounders \\
(Dis/ \\
Com)
\end{tabular} \\
\hline 1991-92 & 79 & 395 & 232 & 51 & 2293 & 1381 & 4045 & 7729 & 10681 & 393 & 20 & 20 & 451 & 426 \\
\hline $1992-93$ & 78 & 395 & 232 & 59 & 2299 & 1399 & 4013 & 7941 & 11182 & 404 & 19 & 20 & 455 & 427 \\
\hline 1993-94 & 79 & 395 & 232 & 59 & 2299 & 1492 & 4032 & 8369 & 11382 & 404 & 19 & 20 & 455 & 427 \\
\hline $1994-95$ & 79 & 398 & 234 & 60 & 2299 & 1541 & 3962 & 8510 & 11308 & 406 & 21 & 20 & 451 & 412 \\
\hline 1995-96 & 79 & 398 & 232 & 63 & 2299 & 1519 & 3551 & 8650 & 11328 & 407 & 21 & 20 & 418 & 398 \\
\hline $1996-97$ & 79 & 398 & 234 & 63 & 2299 & 1500 & 3748 & 8272 & 11328 & 411 & 21 & 20 & 443 & 371 \\
\hline 1997-98 & 80 & 401 & 231 & 64 & 2299 & 1586 & 3639 & 9138 & 11416 & 413 & 21 & 20 & 386 & 387 \\
\hline 1998-99 & 80 & 401 & 231 & 64 & 2299 & 1595 & 3847 & 9334 & 11440 & 421 & 21 & 20 & 371 & 385 \\
\hline 1999-00 & 78 & 402 & 231 & 64 & 2299 & 1415 & 3649 & 8224 & 10878 & 423 & 21 & 20 & 384 & 379 \\
\hline 2000-01 & 78 & 402 & 229 & 64 & 2299 & 1610 & 3746 & 8803 & 10878 & 433 & 21 & 20 & 416 & 365 \\
\hline 2001-02 & 79 & 402 & 229 & 64 & 2299 & 1605 & 3582 & 8548 & 10944 & 434 & 20 & 20 & 404 & 370 \\
\hline 2002-03 & 79 & 403 & 229 & 64 & 2299 & 1770 & 3724 & 8595 & 11044 & 446 & 20 & 20 & 442 & 360 \\
\hline 2003-04 & 79 & 408 & 228 & 65 & 2299 & 1837 & 3966 & 8714 & 11082 & 468 & 20 & 20 & 414 & 355 \\
\hline 2004-05 & 79 & 408 & 228 & 72 & 2433 & 1828 & 3719 & 8389 & 11082 & 470 & 20 & 20 & 461 & 410 \\
\hline 2005-06 & 60 & 409 & 193 & 81 & 2433 & 1839 & 3403 & 8242 & 9584 & 483 & 19 & 20 & 454 & 379 \\
\hline 2006-07 & 61 & 409 & 193 & 84 & 2433 & 1548 & 3998 & 8590 & 9614 & 477 & 19 & 20 & 419 & 482 \\
\hline 2007-08 & 67 & 416 & 193 & 82 & 2433 & 1441 & 4088 & 7449 & 9866 & 477 & 19 & 21 & 450 & 457 \\
\hline 2008-09 & 68 & 420 & 193 & 84 & 2433 & 1554 & 3806 & 8154 & 9986 & 481 & 19 & 22 & 434 & 411 \\
\hline 2009-10 & 69 & 429 & 193 & 85 & 2465 & 1205 & 3138 & 5504 & 10006 & 437 & 20 & 20 & 427 & 406 \\
\hline 2010-11 & 69 & 429 & 193 & 86 & 2465 & 1538 & 3991 & 7408 & 10006 & 462 & 17 & 20 & 402 & 459 \\
\hline 2011-12 & 69 & 431 & 193 & 86 & 2465 & 1593 & 4078 & 7514 & 10028 & 468 & 17 & 23 & 440 & 452 \\
\hline Min. & 60 & 395 & 193 & 51 & 2293 & 1205 & 3138 & 5504 & 9584 & 393 & 17 & 20 & 371 & 355 \\
\hline Max. & 80 & 431 & 234 & 86 & 2465 & 1839 & 4088 & 9334 & 11440 & 483 & 21 & 23 & 461 & 482 \\
\hline Range & 20 & 36 & 41 & 35 & 172 & 634 & 950 & 3830 & 1856 & 90 & 4 & 3 & 90 & 127 \\
\hline Mean & 75 & 407 & 218 & 70 & 2354 & 1562 & 3796 & 8194 & 10717 & 439 & 20 & 20 & 428 & 406 \\
\hline S.D. & 6.560 & 11.493 & 18.357 & 11.041 & 73.548 & 159.382 & 247.282 & 800.432 & 651.474 & 30.490 & 1.221 & 0.784 & 26.536 & 35.987 \\
\hline CV (\%) & 8.747 & 2.824 & 8.421 & 15.773 & 3.124 & 10.204 & 6.514 & 9.769 & 6.079 & 6.945 & 6.105 & 3.920 & 6.200 & 8.864 \\
\hline CGR(\%) & -1.094 & 0.401 & -1.193 & 2.429 & 0.401 & 0.300 & -0.200 & -0.797 & -0.797 & 1.005 & -0.598 & 0.300 & -0.049 & 0.401 \\
\hline
\end{tabular}

Source: Data is collected from Statistical Abstracts of Haryana (Various Issues); Descriptive statistics is computed by researchers.

However, CHCs have experienced highest CAGR of 2.429 per cent in their number but this indicator also have largest coefficient of variation $(\mathrm{CV})$ of

Journal of Technology Management for Growing Economies, Volume 9, Number 1, April 2018 
15.773 per cent thereby revealing high dispersions in the CHCs' number in the State during 1991-92 to 2011-12. Moreover, number of nurses has increased from 4045 in 1991-92 to 4078 in 2011-12 yet their CAGR is -0.200 per cent. Meanwhile, the number of PHCs have just 0.401 per cent CAGR but they possess least variations $(\mathrm{CV}=2.824 \%)$ over the years.

Also, it is a serious cause of concern that among seven indicators having negative CAGR, hospitals, dispensaries, other staff, beds and unani instituions are found to be lesser in number during the year 2011-12 than their average. Another point worthy to be mentioned is that indicators including PHCs, $\mathrm{CHCs}$, SCs, and homoeopathic institutions are found to attain maximum number in 2011-12 among twenty one year period whereas dispensaries and unani institutions stood at their minimum number for the same year.

However, in case of medical institutions sub centers are found highest in number $(\bar{X}=2354)$ with followed by ayurvedic institutions $(\bar{X}=439)$ and PHCs $(\bar{X}=407)$. Similarly, with regard to medical staff, the average number of doctors, nurses and other staff are observed as 1562, 3796 and 8194 while for vaidyas/hakims and dispensers/compounders average number is 428 and 406 respectively. In totality, number of allopathic medical institutions and their staff are much higher than ayurvedic, unani and homoeopathic institutions and their medical staff.

Next, this data is put into further analysis in order to attain second objective of getting a composite index score by combining all these indicators or variables. Thus, the data as revealed in table 2 is an input for further analysis in next section.

\section{2). Composite Index Construction for Health Infrastructure}

In order to prepare composite index of health infrastructure, step by step procedure is described in following sub-sections:

\section{1). Normalization of Indicators of Health Infrastructure}

As a preliminary step of constructing an index, normalization is required when the data is obtained in different measurement units to convert it into identical measures. Present data on indicators of health infrastructure have the same unit of measurement, as the entries in all the cells (table 2) denote the numbers. But, then also to convert that data into a specified range [here a range of 0 to 1], the given data is normalized by using a 'Linear Scaling Technique' also called 'Min-Max Normalization' (OECD, 2008; Sharpe and Andrews, 2012). Under this technique, minimum value of a variable in its data series is subtracted from the particular value for which normalization is undertaken and the resultant is divided by the range (difference between maximum and minimum value of this particular variable) of its data series. In this way, the normalized data comes up within a limit of 0 to 1 .

Journal of Technology Management for Growing Economies, Volume 9, Number 1, April 2018
Construction

of Health

Infrastructure 
Goel, M. M. Garg, I.

$$
\text { Mathematically, Normalized Value }=\frac{\text { Indicator value }- \text { Minimum value }}{\text { Maximum value-Minimum value }}
$$

To elaborate fully, suppose, indicator or variable 'Hos' (Hospitals) is to be normalized for the year 1991-92 when they were 79. In table 2, in data series of 'Hos', minimum value is 60 and the maximum value is 80 . Now, for normalization, subtract minimum value (60) from indicator value (79) and obtain resultant 19 , which has to be divided by the subtraction of maximum (80) and minimum value (60) that is 20 . The normalized value is 0.950 for an indicator value of 79 . The same process is applied to all the values for all indicators or variables and results are shown in table 3 which are used as an input for Principal Component Analysis.

Table 3: Normalized Indicators of Health Infrastructure

\begin{tabular}{|c|c|c|c|c|c|c|c|c|c|c|c|c|c|c|}
\hline \multirow{3}{*}{ Years } & \multicolumn{9}{|c|}{ Infrastructure in Allopathic Institutions } & \multicolumn{5}{|c|}{ Infrastructure in AYUSH Institutions } \\
\hline & \multicolumn{5}{|c|}{ Medical Institutions } & \multicolumn{3}{|c|}{ Medical Staff } & \multirow[b]{2}{*}{$\begin{array}{l}\text { Beds } \\
(\mathrm{Nm})\end{array}$} & \multicolumn{3}{|c|}{ Medical Institutions } & \multicolumn{2}{|c|}{ Medical Staff } \\
\hline & $\begin{array}{c}\text { Hos } \\
(\mathrm{Nm})\end{array}$ & $\begin{array}{c}\text { PHCs } \\
(\mathrm{Nm})\end{array}$ & $\begin{array}{c}\text { Dis } \\
(\mathbf{N m})\end{array}$ & $\begin{array}{c}\text { CHCs } \\
(\mathrm{Nm})\end{array}$ & $\begin{array}{c}\text { SCs } \\
(\mathrm{Nm})\end{array}$ & $\begin{array}{c}\text { Doc } \\
(\mathrm{Nm})\end{array}$ & $\begin{array}{l}\text { Nur } \\
\text { (Nm) }\end{array}$ & $\begin{array}{c}\text { OS } \\
(\mathrm{Nm})\end{array}$ & & $\begin{array}{c}\text { AIs } \\
(\mathrm{Nm})\end{array}$ & $\begin{array}{c}\text { UIs } \\
(\mathbf{N m})\end{array}$ & $\begin{array}{c}\text { HIs } \\
(\mathrm{Nm})\end{array}$ & $\begin{array}{c}\mathrm{Va} / \\
\mathrm{Ha} \\
(\mathrm{Nm})\end{array}$ & $\begin{array}{l}\text { Dis/ } \\
\text { Com } \\
(\mathrm{Nm})\end{array}$ \\
\hline 1991-92 & 0.950 & 0.000 & 0.951 & 0.000 & 0.000 & 0.278 & 0.955 & 0.581 & 0.591 & 0.000 & 0.750 & 0.000 & 0.889 & 0.559 \\
\hline $1992-93$ & 0.900 & 0.000 & 0.951 & 0.229 & 0.035 & 0.306 & 0.921 & 0.636 & 0.861 & 0.122 & 0.500 & 0.000 & 0.933 & 0.567 \\
\hline 1993-94 & 0.950 & 0.000 & 0.951 & 0.229 & 0.035 & 0.453 & 0.941 & 0.748 & 0.969 & 0.122 & 0.500 & 0.000 & 0.933 & 0.567 \\
\hline $1994-95$ & 0.950 & 0.083 & 1.000 & 0.257 & 0.035 & 0.530 & 0.867 & 0.785 & 0.929 & 0.144 & 1.000 & 0.000 & 0.889 & 0.449 \\
\hline $1995-96$ & 0.950 & 0.083 & 0.951 & 0.343 & 0.035 & 0.495 & 0.435 & 0.821 & 0.940 & 0.156 & 1.000 & 0.000 & 0.522 & 0.339 \\
\hline $1996-97$ & 0.950 & 0.083 & 1.000 & 0.343 & 0.035 & 0.465 & 0.642 & 0.723 & 0.940 & 0.200 & 1.000 & 0.000 & 0.800 & 0.126 \\
\hline $1997-98$ & 1.000 & 0.167 & 0.927 & 0.371 & 0.035 & 0.601 & 0.527 & 0.949 & 0.987 & 0.222 & 1.000 & 0.000 & 0.167 & 0.252 \\
\hline 1998-99 & 1.000 & 0.167 & 0.927 & 0.371 & 0.035 & 0.615 & 0.746 & 1.000 & 1.000 & 0.311 & 1.000 & 0.000 & 0.000 & 0.236 \\
\hline 1999-00 & 0.900 & 0.194 & 0.927 & 0.371 & 0.035 & 0.331 & 0.538 & 0.710 & 0.697 & 0.333 & 1.000 & 0.000 & 0.144 & 0.189 \\
\hline 2000-01 & 0.900 & 0.194 & 0.878 & 0.371 & 0.035 & 0.639 & 0.640 & 0.861 & 0.697 & 0.444 & 1.000 & 0.000 & 0.500 & 0.079 \\
\hline 2001-02 & 0.950 & 0.194 & 0.878 & 0.371 & 0.035 & 0.631 & 0.467 & 0.795 & 0.733 & 0.456 & 0.750 & 0.000 & 0.367 & 0.118 \\
\hline 2002-03 & 0.950 & 0.222 & 0.878 & 0.371 & 0.035 & 0.891 & 0.617 & 0.807 & 0.787 & 0.589 & 0.750 & 0.000 & 0.789 & 0.039 \\
\hline 2003-04 & 0.950 & 0.361 & 0.854 & 0.400 & 0.035 & 0.997 & 0.872 & 0.838 & 0.807 & 0.833 & 0.750 & 0.000 & 0.478 & 0.000 \\
\hline 2004-05 & 0.950 & 0.361 & 0.854 & 0.600 & 0.814 & 0.983 & 0.612 & 0.753 & 0.807 & 0.856 & 0.750 & 0.000 & 1.000 & 0.433 \\
\hline 2005-06 & 0.000 & 0.389 & 0.000 & 0.857 & 0.814 & 1.000 & 0.279 & 0.715 & 0.000 & 1.000 & 0.500 & 0.000 & 0.922 & 0.189 \\
\hline 2006-07 & 0.050 & 0.389 & 0.000 & 0.943 & 0.814 & 0.541 & 0.905 & 0.806 & 0.016 & 0.933 & 0.500 & 0.000 & 0.533 & 1.000 \\
\hline 2007-08 & 0.350 & 0.583 & 0.000 & 0.886 & 0.814 & 0.372 & 1.000 & 0.508 & 0.152 & 0.933 & 0.500 & 0.333 & 0.878 & 0.803 \\
\hline 2008-09 & 0.400 & 0.694 & 0.000 & 0.943 & 0.814 & 0.550 & 0.703 & 0.692 & 0.217 & 0.978 & 0.500 & 0.667 & 0.700 & 0.441 \\
\hline 2009-10 & 0.450 & 0.944 & 0.000 & 0.971 & 1.000 & 0.000 & 0.000 & 0.000 & 0.227 & 0.489 & 0.750 & 0.000 & 0.622 & 0.402 \\
\hline 2010-11 & 0.450 & 0.944 & 0.000 & 1.000 & 1.000 & 0.525 & 0.898 & 0.497 & 0.227 & 0.767 & 0.000 & 0.000 & 0.344 & 0.819 \\
\hline 2011-12 & 0.450 & 1.000 & 0.000 & 1.000 & 1.000 & 0.612 & 0.989 & 0.525 & 0.239 & 0.833 & 0.000 & 1.000 & 0.767 & 0.764 \\
\hline Mean & 0.733 & 0.336 & 0.616 & 0.535 & 0.357 & 0.563 & 0.693 & 0.702 & 0.611 & 0.511 & 0.690 & 0.095 & 0.628 & 0.399 \\
\hline S.D. & 0.328 & 0.319 & 0.448 & 0.315 & 0.428 & 0.251 & 0.260 & 0.209 & 0.351 & 0.339 & 0.305 & 0.261 & 0.295 & 0.283 \\
\hline
\end{tabular}

Source: Researchers' Calculations of Normalization

Note: 'Nm' symbolizes that the shown variables have now been normalized

Journal of Technology Management for Growing Economies, Volume 9, Number 1, April 2018 


\section{2). Principal Component Analysis for Composite Index}

Principal component analysis of the normalized data is performed with the help of SPSS (version 20) and resultant output is shown under following headings:

- Correlation Matrix, Kaiser-Meyer-Olkin (KMO) Measure and Bartlett's Test

To start the analysis, it is necessary to test that whether present data is adequate for principal component analysis (PCA). In this regard, Correlation matrix (showing scores of correlation among variables), Kaiser-Meyer-Olkin (KMO) Measure of Sampling Adequacy and Bartlett's Test of Sphericity are computed by SPSS system (Constantin, 2014).

Since, the PCA method depends on the correlations between sets of variables. Therefore, it becomes imperative to examine the correlation among variables undertaken. More clearly, the correlation scores clarify that whether the PCA will be meaningful or not. The correlations between individual variables has to be higher than 0.30 for the analysis to provide significant results. However, low scores of some of the correlations do not create problem. But if, most of the correlations score near about zero, then method lose its usefulness (Mooi and Sarstedt, 2011; Hoque, 2014). The correlation matrix which is one of the output of PCA, are presented in table 4.

Table 4: Correlation Matrix, KMO and Bartlett's Test

\begin{tabular}{|c|c|c|c|c|c|c|c|c|c|c|c|c|c|c|}
\hline \multicolumn{15}{|c|}{ Correlation Matrix } \\
\hline $\begin{array}{c}\text { Health } \\
\text { Indicators }\end{array}$ & Hos & PHCs & Dis & CHCs & SCs & Doc & Nur & os & Beds & AIs & UIs & HIs & $\mathrm{Va} / \mathrm{Ha}$ & \begin{tabular}{|l} 
Dis/ \\
Com
\end{tabular} \\
\hline Hos & 1.000 & & & & & & & & & & & & & \\
\hline PHCs & $-.654 *$ & 1.000 & & & & & & & & & & & & \\
\hline Dis & $.938^{*}$ & $-.859^{*}$ & 1.000 & & & & & & & & & & & \\
\hline CHCs & $-.859^{*}$ & $.905^{*}$ & $-.951 *$ & 1.000 & & & & & & & & & & \\
\hline SCs & $-.827^{*}$ & $.880^{*}$ & $-.921 *$ & $.945^{*}$ & 1.000 & & & & & & & & & \\
\hline Doc & $.016^{\mathrm{ns}}$ & $-.070^{\mathrm{ns}}$ & $.089^{\mathrm{ns}}$ & $.025^{\mathrm{ns}}$ & $-.013^{\mathrm{ns}}$ & 1.000 & & & & & & & & \\
\hline Nur & $.060^{\mathrm{ns}}$ & $-.092^{\mathrm{ns}}$ & $.044^{\mathrm{ns}}$ & $-.126^{\mathrm{ns}}$ & $-.076^{\mathrm{ns}}$ & $.031^{\mathrm{ns}}$ & 1.000 & & & & & & & \\
\hline OS & $.424 * *$ & $-.644^{*}$ & $.569^{*}$ & $-.495^{* *}$ & $-.600^{*}$ & $.595^{*}$ & $.232^{\mathrm{ns}}$ & 1.000 & & & & & & \\
\hline Beds & $.952 *$ & $-.740^{*}$ & $.949^{*}$ & $-.852^{*}$ & $-.849 *$ & $.081^{\mathrm{ns}}$ & $.039^{\mathrm{ns}}$ & $.546^{*}$ & 1.000 & & & & & \\
\hline AIs & $-.732 *$ & $.695^{*}$ & $-.766^{*}$ & $.825^{*}$ & $.769^{*}$ & $.477^{* *}$ & $.008^{\mathrm{ns}}$ & $-.154^{\mathrm{ns}}$ & $-.744^{*}$ & 1.000 & & & & \\
\hline UIs & $.620^{*}$ & $-.672^{*}$ & $.712^{*}$ & $-.647^{*}$ & $-.699 *$ & $-.023^{\mathrm{ns}}$ & $-.401 * *$ & $.429 * *$ & $.657^{*}$ & $-.547^{*}$ & 1.000 & & & \\
\hline HIs & $-.370^{* *}$ & $.591^{*}$ & $-.526^{*}$ & $.518^{*}$ & $.493 * *$ & $-.017^{\mathrm{ns}}$ & $.298^{* * *}$ & $-.228^{\mathrm{ns}}$ & $-.429 * *$ & $.438^{* *}$ & $-.552 *$ & 1.000 & & \\
\hline $\mathrm{Va} / \mathrm{Ha}$ & $-.181^{\mathrm{ns}}$ & $-.035^{\mathrm{ns}}$ & $-.114^{\mathrm{ns}}$ & $.017^{\mathrm{ns}}$ & $.216^{\mathrm{ns}}$ & $.052^{\text {ns }}$ & $.205^{\mathrm{ns}}$ & $.306^{* * *}$ & $-.170^{\mathrm{ns}}$ & $.097^{\mathrm{ns}}$ & $-.288^{\text {ns }}$ & $.176^{\mathrm{ns}}$ & 1.000 & \\
\hline Dis/Com & $-.538^{*}$ & $.409 * *$ & $-.568^{*}$ & $.483^{* *}$ & $.593^{*}$ & $-.383 * *$ & $.524 *$ & $-.386^{* *}$ & $-.531 *$ & $.232^{\mathrm{ns}}$ & \begin{tabular}{|l|l|}
$-.672 *$ \\
\end{tabular} & $.357 * * *$ & $.260^{\mathrm{ns}}$ & 1.000 \\
\hline \multicolumn{15}{|c|}{ KMO and Bartlett's Test } \\
\hline \multicolumn{5}{|c|}{$\begin{array}{c}\begin{array}{c}\text { Kaiser-Meyer-Olkin Measure of Sampling } \\
\text { Adequacy }\end{array} \\
\end{array}$} & \multicolumn{5}{|c|}{ KMO Measure } & \multicolumn{5}{|c|}{0.460} \\
\hline \multirow{3}{*}{\multicolumn{5}{|c|}{ Bartlett's Test of Sphericity }} & \multicolumn{5}{|c|}{ Approx. Chi-Square } & \multicolumn{5}{|c|}{399.705} \\
\hline & & & & & \multicolumn{5}{|c|}{ df } & \multicolumn{5}{|c|}{91} \\
\hline & & & & & \multicolumn{5}{|c|}{ Sig. } & \multicolumn{5}{|c|}{0.000} \\
\hline
\end{tabular}

Source: Researchers' Calculations

Note: $* 1$ per cent significance; $* * 5$ per cent significance; $* * * 10$ per cent significance; ${ }^{\text {ns }}$ not significant
Construction

of Health

Infrastructure 
Goel, M. M.

Garg, I.

112
The correlation matrix is a rectangular arrangement of numbers showing the correlation coefficients between one variable and every other variables. It is evident from table 4 that the all elements on principal diagonal are 1 since correlation coefficient between a variable with itself is always unity. Below this principal diagonal, the some correlation coefficients are positive and some are negative thereby implying that some of the variables move in same direction with other variables, some varies oppositely with others. Further, correlations between indicator variables are found to be of high, moderate and low degree which are significant either at 1 per cent, or 5 per cent, or 10 per cent level of significance. However, some indicator variables show insignificant correlation with other variables, for example, doctors, nurses and vaidyas/hakims have insignificant correlation with most of the variables. This pattern suggests some variables may flow together and some others may go differently. Thus, possibly certain components or latent variables or factors can be obtained for these variables.

Next output, Kaiser-Meyer-Olkin (KMO) statistic, a measure of the strength of relationship among variables, indicates whether the correlations between variables can be explained by other variables in the dataset. Its value varies between 0 and 1 . The data is considered suitable for PCA if KMO statistic is equal or higher than 0.50. In the present context, the value of KMO (0.460) is approximately equal to 0.5 therefore; data is suitable for the application of PCA.

Moreover, the Bartlett's test is another indicator of judging that whether original variables are sufficiently correlated. It is used to test the null hypothesis that the correlation matrix is an identity matrix that is, in which diagonal elements are 1 and others are 0 . This implies that all variables are perfectly correlated with themselves but uncorrelated with others. Alternatively, correlation matrix is not identity matrix thereby implying that there are some degree of correlation between variables. To test the null hypothesis that all correlation coefficients are zero or not significant, chi-square statistic is computed under Bartlett test. The value of approximate chi-square statistic is found to be 399.705 with 91 degrees of freedom, which is significant at 0.000 level of significance which is under the accepted range of level of significance (p-value) 0.05 . On this basis, null hypothesis that is variables are uncorrelated or correlation matrix is an identity matrix is rejected and alternative hypothesis is accepted which means original variables are correlated which is compulsory for the adequacy of PCA.

Journal of Technology Management for Growing Economies, Volume 9, Number 1, April 2018 
Thus, significant scores of correlation coefficients and results of $\mathrm{KMO}$ and Bartlett's test show that principal component analysis is preferable.

\section{- Decision for Number of Components}

After passing the above tests, next step is to identify the number of factors or principal components or latent variables that can represent all originally undertaken variables. For the same, eigenvalue-one criterion (Kaiser's criterion or latent root criterion), scree plot and total amount of variance extracted are the methods that can be used. But, present study adopts eigenvalue-one criterion according to the standard practice of decision as mentioned by OECD (2008) and Sharpe and Andrews (2012). Under, eigenvalue-one criterion, those factors or principal components or latent variables are selected which possess eigenvalues larger than 1 , individual variance explained more than 10 per cent; and cumulative contribution to overall variance more than 60 per cent. In table 5 , initial and rotated eigenvalues are presented as another output of PCA.

Table 5: Eigenvalues (Initial and Rotated) and Components

\begin{tabular}{|c|c|c|c|c|c|c|c|c|c|}
\hline \multirow{2}{*}{ Component } & \multicolumn{3}{|c|}{ Initial Eigenvalues } & \multicolumn{3}{c|}{$\begin{array}{c}\text { Extraction Sums of Squared } \\
\text { Loadings }\end{array}$} & \multicolumn{3}{c|}{ Rotation Sums of Squared Loadings } \\
\cline { 2 - 10 } & Total & $\begin{array}{c}\text { \% of } \\
\text { Variance }\end{array}$ & $\begin{array}{c}\text { Cumulative } \\
\text { \% }\end{array}$ & Total & $\begin{array}{c}\text { \% of } \\
\text { Variance }\end{array}$ & $\begin{array}{c}\text { Cumulative } \\
\text { \% }\end{array}$ & Total & $\begin{array}{c}\text { \% of Vari- } \\
\text { ance }\end{array}$ & Cumulative \% \\
\hline $\mathbf{1}$ & 7.610 & 54.359 & 54.359 & 7.610 & 54.359 & 54.359 & 7.047 & 50.334 & 50.334 \\
\hline $\mathbf{2}$ & 1.889 & 13.496 & 67.855 & 1.889 & 13.496 & 67.855 & 2.254 & 16.099 & 66.433 \\
\hline $\mathbf{3}$ & 1.752 & 12.515 & 80.370 & 1.752 & 12.515 & 80.370 & 1.951 & 13.937 & 80.370 \\
\hline $\mathbf{4}$ & .998 & 7.129 & 87.499 & & & & & & \\
\hline $\mathbf{5}$ & .758 & 5.415 & 92.914 & & & & & & \\
\hline $\mathbf{6}$ & .418 & 2.983 & 95.897 & & & & & & \\
\hline $\mathbf{7}$ & .247 & 1.768 & 97.665 & & & & & & \\
\hline $\mathbf{8}$ & .192 & 1.375 & 99.040 & & & & & & \\
\hline $\mathbf{9}$ & .054 & .386 & 99.427 & & & & & & \\
\hline $\mathbf{1 0}$ & .045 & .324 & 99.751 & & & & & & \\
\hline $\mathbf{1 1}$ & .015 & .108 & 99.859 & & & & & & \\
\hline $\mathbf{1 2}$ & .012 & .083 & 99.941 & & & & & & \\
\hline $\mathbf{1 3}$ & .007 & .052 & 99.994 & & & & & & \\
\hline $\mathbf{1 4}$ & .001 & .006 & 100.000 & & & & & & \\
\hline
\end{tabular}

Source: Researchers' Calculations

It is cleared from initial eigenvalues in the table that the number of components is equal to number of variables selected in the study and every component has an eigenvalue showing the variance extracted by itself. But, only first three components are possessing the eigenvalue greater than 1 (7.610, 1.889 and 1.752) and thus, fourteen indicators are reduced to these three set of components as shown in table under column extraction sums of squared loadings. For further clarification about retained components, rotation has been applied. It is found that there exist three components with eigenvalues

Journal of Technology Management for Growing Economies, Volume 9, Number 1, April 2018
Construction

of Health

Infrastructure 
Goel, M. M. Garg, I.

7.047, 2.254 and 1.951 which are some different from initial eigenvalues but their summation is same with initial eigenvalues of first three components. After rotation, these components individually explain 50.334 per cent, 16.099 per cent and 13.937 per cent of variance (well above suggested 10 per cent) but cumulatively explain 80.370 per cent of variance which are notably above the suggested criterion of 60 per cent. With this analysis, three components are retained which are able to represent fourteen variables selected for study.

\section{- Component Matrix and Loadings}

Table 6 is a triad for component loadings, squared component loadings and squared loadings scaled to unity sum. Component loadings are the correlations between variables and the latent components. These are used to examine which component is formed with which of the variables. This information is provided by PCA in its output named initial or un-rotated component loading matrix.

Table 6: Rotated Component Loadings Matrices

\begin{tabular}{|c|c|c|c|c|c|c|c|c|c|}
\hline \multirow[t]{3}{*}{$\begin{array}{l}\text { Indicator } \\
\text { Variables }\end{array}$} & \multicolumn{3}{|c|}{ Component Loadings } & \multicolumn{3}{|c|}{$\begin{array}{l}\text { Squared Component } \\
\text { Loadings }\end{array}$} & \multicolumn{3}{|c|}{$\begin{array}{l}\text { Squared Scaled to Unity Sum } \\
\text { (Domain Weight) }\end{array}$} \\
\hline & \multicolumn{3}{|c|}{ Component } & \multicolumn{3}{|c|}{ Component } & \multicolumn{3}{|c|}{ Component } \\
\hline & 1 & 2 & 3 & 1 & 2 & 3 & 1 & 2 & 3 \\
\hline Hos & -.888 & -.136 & .079 & 0.788 & 0.018 & 0.006 & 0.112 & 0.008 & 0.003 \\
\hline PHCs & .891 & .055 & -.174 & 0.795 & 0.003 & 0.030 & 0.113 & 0.001 & 0.016 \\
\hline Dis & -.959 & -.155 & .161 & 0.920 & 0.024 & 0.026 & 0.131 & 0.011 & 0.013 \\
\hline CHCs & .975 & .045 & -.052 & 0.951 & 0.002 & 0.003 & 0.135 & 0.001 & 0.001 \\
\hline SCs & .937 & .164 & -.145 & 0.878 & 0.027 & 0.021 & 0.125 & 0.012 & 0.011 \\
\hline Doc & .106 & -.081 & .945 & 0.011 & 0.007 & 0.893 & 0.002 & 0.003 & 0.458 \\
\hline Nur & -.177 & .900 & .188 & 0.031 & 0.810 & 0.036 & 0.004 & 0.359 & 0.018 \\
\hline OS & -.504 & -.027 & .768 & 0.254 & 0.001 & 0.591 & 0.036 & 0.000 & 0.303 \\
\hline Beds & -.907 & -.147 & .154 & 0.822 & 0.022 & 0.024 & 0.117 & 0.010 & 0.012 \\
\hline AIs & .869 & .063 & .418 & 0.755 & 0.004 & 0.175 & 0.107 & 0.002 & 0.090 \\
\hline UIs & -.654 & -.608 & .045 & 0.428 & 0.370 & 0.002 & 0.061 & 0.164 & 0.001 \\
\hline HIs & .499 & .463 & .049 & 0.249 & 0.214 & 0.002 & 0.035 & 0.095 & 0.001 \\
\hline $\mathrm{Va} / \mathrm{Ha}$ & .065 & .490 & -.092 & 0.004 & 0.240 & 0.008 & 0.001 & 0.106 & 0.004 \\
\hline Dis/Com & .400 & .716 & -.367 & 0.160 & 0.513 & 0.135 & 0.023 & 0.228 & 0.069 \\
\hline \multicolumn{4}{|c|}{ Explained Variance } & 7.047 & 2.254 & 1.951 & 1.000 & 1.000 & 1.000 \\
\hline \multicolumn{4}{|c|}{ Total Variance } & \multicolumn{3}{|c|}{11.252} & & & \\
\hline \multicolumn{4}{|c|}{$\begin{array}{l}\text { Explained Variance/Total Variance } \\
\text { (Component Weight) }\end{array}$} & 0.626 & 0.200 & 0.173 & & & \\
\hline
\end{tabular}

Source: Researchers' Calculations

Note: Columns under 'Component Loadings' is the output of PCA.

Journal of Technology Management for Growing Economies, Volume 9, Number 1, April 2018 
In this matrix, sometimes, it becomes difficult to recognize that which variable should be included in which component because various variables load moderately on each component. To overcome this problem, varimax rotation has been applied; as a result of which each original variable tends to be associated with one (or a small number) of retained components, and each component represents only a small number of variables (Abdi and Williams, 2010). However for the sake of simplicity, the rotated component loading matrix is shown in table 6In order to check which indicator variable load on which component, a criterion of component loadings greater than 0.5 is employed (Hair et al., 2010). It can be seen from the left side of table that first component is formed by Hos (hospitals), PHCs, Dis (dispensaries), CHCs, SCs, Beds and AIs (ayurvedic institutions), UIs (unani institutions) and HIs (homoeopathic institutions) since the component loadings of these variables are high on the first component among three components. Component two is a formation of variables Nur (nurses), $\mathrm{Va} / \mathrm{Ha}$ (vaidyas/hakims) and Dis/ Com (dispensers/compounders). On the same notions, component three is a conglomerate of variable namely Doc (doctors) and OS (other staff).

Now, at the middle of table there are squared component loadings (obtained by squaring the component loadings) which explain the amount of variation of the indicator variables that the latent components explain. Below the matrix of 'squared component loadings' explained variance of three components are displayed. This is attained by adding the square component loadings of components one, two and three respectively. Actually, these are the three eigenvalues, obtained after rotation. Now, total variance is the addition of three values of explained variance [7.047+2.254+1.951]. Explained variance when divided by total variance gives 'component weight'.

Table 7: Weighted Scores for Variables

\begin{tabular}{|c|c|c|c|c|}
\hline Indicators & $\begin{array}{c}\text { Domain } \\
\text { Weight (I) }\end{array}$ & $\begin{array}{c}\text { Component } \\
\text { Weight (II) }\end{array}$ & $\begin{array}{c}\text { Weight Score } \\
\text { (I*II) III } \\
\text { Total=0.856 }\end{array}$ & $\begin{array}{c}\text { Resulting } \\
\text { Weight } \\
\text { III/0.856 }\end{array}$ \\
\hline Hos & $\mathbf{0 . 1 1 2}$ & 0.626 & 0.070 & 0.082 \\
\hline PHCs & $\mathbf{0 . 1 1 3}$ & 0.626 & 0.071 & 0.083 \\
\hline Dis & $\mathbf{0 . 1 3 1}$ & 0.626 & 0.082 & 0.096 \\
\hline CHCs & $\mathbf{0 . 1 3 5}$ & 0.626 & 0.085 & 0.099 \\
\hline SCs & $\mathbf{0 . 1 2 5}$ & 0.626 & 0.078 & 0.091 \\
\hline Doc & $\mathbf{0 . 4 5 8}$ & 0.173 & 0.079 & 0.093 \\
\hline Nur & $\mathbf{0 . 3 5 9}$ & 0.200 & 0.072 & 0.084 \\
\hline
\end{tabular}

Journal of Technology Management for Growing Economies, Volume 9, Number 1, April 2018
Construction

of Health

Infrastructure 
Goel, M. M. Garg, I.

\begin{tabular}{|c|c|c|c|c|}
\hline Indicators & $\begin{array}{c}\text { Domain } \\
\text { Weight (I) }\end{array}$ & $\begin{array}{c}\text { Component } \\
\text { Weight (II) }\end{array}$ & $\begin{array}{c}\text { Weight Score } \\
\text { (I*II) III } \\
\text { Total=0.856 }\end{array}$ & $\begin{array}{c}\text { Resulting } \\
\text { Weight } \\
\text { III/0.856 }\end{array}$ \\
\hline OtSt & $\mathbf{0 . 3 0 3}$ & 0.173 & 0.052 & 0.061 \\
\hline Beds & $\mathbf{0 . 1 1 7}$ & 0.626 & 0.073 & 0.086 \\
\hline AyHos & $\mathbf{0 . 1 0 7}$ & 0.626 & 0.067 & 0.078 \\
\hline UnHos & $\mathbf{0 . 0 6 1}$ & 0.626 & 0.038 & 0.045 \\
\hline HoHos & $\mathbf{0 . 0 3 5}$ & 0.626 & 0.022 & 0.026 \\
\hline Va/Ha & $\mathbf{0 . 1 0 6}$ & 0.200 & 0.021 & 0.025 \\
\hline Dis/Com & $\mathbf{0 . 2 2 8}$ & 0.200 & 0.046 & 0.053 \\
\hline
\end{tabular}

Source: Researchers' Calculations

Third part of table 'squared loadings scaled to unity sum' is attained by dividing squared loadings in each component by the explained variance of respective component, and the values obtained are entitled as 'domain weight' for all original variables rests under various components. Now, the 'component weight' and 'domain weight' are used in table 7 to arrive at the final weights.

In above table 7, column 'domain weight' shows the weight of the original variable in the component in which it falls and is obtained by squared loadings scaled to unity sum shown in third part of table 6 . Similarly, each variable has that component weight in which this variable lies and on this basis column of 'component weight' is prepared. For example, variable 'Hos' fell under first component whose weight is 0.626 as calculated in table 6 .

Table 8: Weighted Variables or Weighted Indicators of Health Infrastructure

\begin{tabular}{|c|c|c|c|c|c|c|c|c|c|c|c|c|c|c|c|}
\hline \multirow{3}{*}{ Years } & \multicolumn{9}{|c|}{ Infrastructure in Allopathic Institutions } & \multicolumn{4}{c|}{ Infrastructure in AYUSH Institutions } \\
\cline { 2 - 14 } & \multicolumn{4}{|c|}{ Medical Institutions } & \multicolumn{3}{|c|}{ Medical Staff } & & \multicolumn{3}{c|}{ Medical Institutions } & \multicolumn{2}{c|}{ Medical Staff } \\
\cline { 2 - 15 }$y$ & Hos & PHCs & Dis & CHCs & SCs & Doc & Nur & OtSt & Beds & AyHos & UnHos & HoHos & Va/Ha & Dis/Com \\
\hline $\mathbf{1 9 9 1 - 9 2}$ & 0.238 & 0.000 & 0.204 & 0.000 & 0.000 & 0.101 & 0.309 & 0.170 & 0.145 & 0.000 & 0.111 & 0.000 & 0.075 & 0.105 \\
\hline $\mathbf{1 9 9 2 - 9 3}$ & 0.225 & 0.000 & 0.204 & 0.072 & 0.007 & 0.111 & 0.298 & 0.186 & 0.211 & 0.028 & 0.074 & 0.000 & 0.079 & 0.106 \\
\hline $\mathbf{1 9 9 3 - 9 4}$ & 0.238 & 0.000 & 0.204 & 0.072 & 0.007 & 0.164 & 0.304 & 0.218 & 0.237 & 0.028 & 0.074 & 0.000 & 0.079 & 0.106 \\
\hline $\mathbf{1 9 9 4 - 9 5}$ & 0.238 & 0.022 & 0.214 & 0.081 & 0.007 & 0.192 & 0.280 & 0.229 & 0.228 & 0.033 & 0.148 & 0.000 & 0.075 & 0.084 \\
\hline $\mathbf{1 9 9 5 - 9 6}$ & 0.238 & 0.022 & 0.204 & 0.107 & 0.007 & 0.179 & 0.141 & 0.240 & 0.230 & 0.036 & 0.148 & 0.000 & 0.044 & 0.063 \\
\hline $\mathbf{1 9 9 6 - 9 7}$ & 0.238 & 0.022 & 0.214 & 0.107 & 0.007 & 0.169 & 0.207 & 0.211 & 0.230 & 0.046 & 0.148 & 0.000 & 0.068 & 0.024 \\
\hline $\mathbf{1 9 9 7 - 9 8}$ & 0.250 & 0.043 & 0.199 & 0.116 & 0.007 & 0.218 & 0.170 & 0.277 & 0.242 & 0.051 & 0.148 & 0.000 & 0.014 & 0.047 \\
\hline
\end{tabular}

Journal of Technology Management for Growing Economies, Volume 9, Number 1, April 2018 


\begin{tabular}{|l|l|l|l|l|l|l|l|l|l|l|l|l|l|l|}
\hline $\mathbf{1 9 9 8 - 9 9}$ & 0.250 & 0.043 & 0.199 & 0.116 & 0.007 & 0.223 & 0.241 & 0.292 & 0.245 & 0.072 & 0.148 & 0.000 & 0.000 & 0.044 \\
\hline $\mathbf{1 9 9 9 - 0 0}$ & 0.225 & 0.050 & 0.199 & 0.116 & 0.007 & 0.120 & 0.174 & 0.207 & 0.171 & 0.077 & 0.148 & 0.000 & 0.012 & 0.035 \\
\hline $\mathbf{2 0 0 0 - 0 1}$ & 0.225 & 0.050 & 0.188 & 0.116 & 0.007 & 0.232 & 0.207 & 0.251 & 0.171 & 0.102 & 0.148 & 0.000 & 0.042 & 0.015 \\
\hline $\mathbf{2 0 0 1 - 0 2}$ & 0.238 & 0.050 & 0.188 & 0.116 & 0.007 & 0.229 & 0.151 & 0.232 & 0.180 & 0.105 & 0.111 & 0.000 & 0.031 & 0.022 \\
\hline $\mathbf{2 0 0 2 - 0 3}$ & 0.238 & 0.058 & 0.188 & 0.116 & 0.007 & 0.323 & 0.199 & 0.236 & 0.193 & 0.136 & 0.111 & 0.000 & 0.067 & 0.007 \\
\hline $\mathbf{2 0 0 3 - 0 4}$ & 0.238 & 0.094 & 0.183 & 0.125 & 0.007 & 0.361 & 0.282 & 0.245 & 0.198 & 0.192 & 0.111 & 0.000 & 0.041 & 0.000 \\
\hline $\mathbf{2 0 0 4 - 0 5}$ & 0.238 & 0.094 & 0.183 & 0.188 & 0.173 & 0.356 & 0.198 & 0.220 & 0.198 & 0.197 & 0.111 & 0.000 & 0.085 & 0.081 \\
\hline $\mathbf{2 0 0 5 - 0 6}$ & 0.000 & 0.101 & 0.000 & 0.268 & 0.173 & 0.363 & 0.090 & 0.209 & 0.000 & 0.230 & 0.074 & 0.000 & 0.078 & 0.035 \\
\hline $\mathbf{2 0 0 6 - 0 7}$ & 0.013 & 0.101 & 0.000 & 0.295 & 0.173 & 0.196 & 0.292 & 0.235 & 0.004 & 0.215 & 0.074 & 0.000 & 0.045 & 0.187 \\
\hline $\mathbf{2 0 0 7 - 0 8}$ & 0.088 & 0.152 & 0.000 & 0.278 & 0.173 & 0.135 & 0.323 & 0.148 & 0.037 & 0.215 & 0.074 & 0.033 & 0.074 & 0.150 \\
\hline $\mathbf{2 0 0 8 - 0 9}$ & 0.100 & 0.181 & 0.000 & 0.295 & 0.173 & 0.199 & 0.227 & 0.202 & 0.053 & 0.225 & 0.074 & 0.066 & 0.059 & 0.083 \\
\hline $\mathbf{2 0 0 9 - 1 0}$ & 0.113 & 0.246 & 0.000 & 0.304 & 0.213 & 0.000 & 0.000 & 0.000 & 0.056 & 0.113 & 0.111 & 0.000 & 0.053 & 0.075 \\
\hline $\mathbf{2 0 1 0 - 1 1}$ & 0.113 & 0.246 & 0.000 & 0.313 & 0.213 & 0.190 & 0.290 & 0.145 & 0.056 & 0.176 & 0.000 & 0.000 & 0.029 & 0.153 \\
\hline $\mathbf{2 0 1 1 - 1 2}$ & 0.113 & 0.260 & 0.000 & 0.313 & 0.213 & 0.222 & 0.320 & 0.153 & 0.059 & 0.192 & 0.000 & 0.100 & 0.065 & 0.143 \\
\hline
\end{tabular}

Construction

of Health

Infrastructure

Source: Authors Calculations

Note: Weighted variables are computed by multiplying each indicator by its respective weight and then divide by indicator's Standard deviation.

Likewise, all variables have domain weight as well as component weight. As a next step, the 'domain weight' and 'component weight' is multiplied (as shown under column 'Weight Score' in table 7) and the resultant is divided by summation of multiplication values to arrive at weight scores. In this way, final weights of each variable are obtained and displayed in the last column under the heading 'Resulting Weight'. The summation of weights in this column is definitely come out to be 1 , and now these weights are ready to be used for a weighed aggregation of variables for getting a composite index.

\section{- Composite Index}

To prepare composite index, firstly, each indicator or variable (normalized) for various years is multiplied by its weight (computed in table 7) and is divided by its standard deviation (obtained from normalized data). In this way all variables will be credited with weighted scores for various years which has to be summated to obtain composite index for every year. 
Goel, M. M.

Garg, I.

118

Table 9: Composite Index of Health Infrastructure

\begin{tabular}{|c|c|c|c|}
\hline Years & $\begin{array}{c}\text { Composite Index } \\
\text { (Aggregation of Weighted } \\
\text { Indicators) }\end{array}$ & $\begin{array}{c}\text { Normalized } \\
\text { Composite Index }\end{array}$ & Ranking \\
\hline $\mathbf{1 9 9 1 - 9 2}$ & 1.458 & 0.168 & $19^{\text {th }}$ \\
\hline $\mathbf{1 9 9 2 - 9 3}$ & 1.601 & 0.305 & $17^{\text {th }}$ \\
\hline $\mathbf{1 9 9 3 - 9 4}$ & 1.731 & 0.431 & $12^{\text {th }}$ \\
\hline $\mathbf{1 9 9 4 - 9 5}$ & 1.831 & 0.527 & $8^{\text {th }}$ \\
\hline $\mathbf{1 9 9 5 - 9 6}$ & 1.659 & 0.361 & $15^{\text {th }}$ \\
\hline $\mathbf{1 9 9 6 - 9 7}$ & 1.691 & 0.392 & $13^{\text {th }}$ \\
\hline $\mathbf{1 9 9 7 - 9 8}$ & 1.782 & 0.480 & $10^{\text {th }}$ \\
\hline $\mathbf{1 9 9 8 - 9 9}$ & 1.880 & 0.574 & $6^{\text {th }}$ \\
\hline $\mathbf{1 9 9 9 - 0 0}$ & 1.541 & 0.248 & $18^{\text {th }}$ \\
\hline $\mathbf{2 0 0 0 - 0 1}$ & 1.754 & 0.453 & $11^{\text {th }}$ \\
\hline $\mathbf{2 0 0 1 - 0 2}$ & 1.660 & 0.362 & $14^{\text {th }}$ \\
\hline $\mathbf{2 0 0 2 - 0 3}$ & 1.879 & 0.573 & $7^{\text {th }}$ \\
\hline $\mathbf{2 0 0 3 - 0 4}$ & 2.077 & 0.764 & $3^{\text {rd }}$ \\
\hline $\mathbf{2 0 0 4 - 0 5}$ & 2.322 & 1.000 & $1^{\text {st }}$ \\
\hline $\mathbf{2 0 0 5 - 0 6}$ & 1.621 & 0.325 & $16^{\text {th }}$ \\
\hline $\mathbf{2 0 0 6 - 0 7}$ & 1.830 & 0.526 & $9^{\text {th }}$ \\
\hline $\mathbf{2 0 0 7 - 0 8}$ & 1.880 & 0.574 & $6^{\text {th }}$ \\
\hline $\mathbf{2 0 0 8 - 0 9}$ & 1.937 & 0.629 & $4^{\text {th }}$ \\
\hline $\mathbf{2 0 0 9 - 1 0}$ & 1.284 & 0.000 & $20^{\text {th }}$ \\
\hline $\mathbf{2 0 1 0 - 1 1}$ & 1.924 & 0.617 & $5^{\text {th }}$ \\
\hline $\mathbf{2 0 1 1 - 1 2}$ & 2.153 & 0.837 & $2^{\text {nd }}$ \\
\hline $54 r e: R e s e r \mid$ & \\
\hline
\end{tabular}

Source: Researchers' Calculations based on previous table 8

To keep the scores of composite index ranging between 0 and 1 , it is necessary to normalize the composite index by subtracting minimum value in the series from each value and then divide the resultant by the difference of maximum and minimum value. In this way, composite index of health infrastructure is constructed and presented in table 9.

\section{3) Ranking of Health Infrastructure in Haryana}

To achieve the third objective, ranks are given to the State of Haryana for health infralstructure in various years as per the calculated index scores. It is cleared from the table 9 that score of health infrastructure index have improved from

Journal of Technology Management for Growing Economies, Volume 9, Number 1, April 2018 
0.168 in the year 1991-92 to 0.527 in 1994-95 and consequently, the rank is also upgraded from $19^{\text {th }}$ to $8^{\text {th }}$ for the same period. But, in the next year the value of index is declined to 0.361 which attain $15^{\text {th }}$ rank. But, in subsequent three years (1996-97, 1997-98 and 1998-99) the rank of health infrastructure become better to $13^{\text {th }}, 10^{\text {th }}$ and $6^{\text {th }}$ with index values $0.392,0.480$ and 0.574 respectively.

Unfortunately, in 1999-00, the index value once again falls and reaches to 0.251 with $18^{\text {th }}$ ranking. But, this situation changes in 2002-03 when index score climbs to 0.573 with rank $7^{\text {th }}$ which is second best over previous years. However, this trend is found to continue in 2003-04 with index score 0.764 attaining $3^{\text {rd }}$ rank and in 2004-05 with 1.000 index score receiving $1^{\text {st }}$ rank. Thus, in 200405 , health infrastructure in the State of Haryana is at best status in comparison with other years. Meanwhile, the situation deviated once again when index score drops to 0.325 in 2005-06 and thus, in one year the rank slips to $16^{\text {th }}$ from $1^{\text {st }}$. In the next three years the index score increases to $0.526,0.574$ and 0.629 respectively and consequently ranks also hiked. It is noteworthy that the years 1998-99 and 2007-08 have same index score $(0.574)$ and rank $\left(6^{\text {th }}\right)$ for health infrastructure status in the State.

However, the worst condition is seen in the year 2009-10, when the value of index become zero. It does not implies the nil availability of health infrastructure in 2009-10; actually, the index score for this year shows least availability of health infrastructural facilities in comparison with other years. It can also be identified from first column of 'Composite index' in table 9 highlighting 1.284 score (without normalization) which is lowest for the year 2009-10. In the next two years, index score is increased to 0.617 with $5^{\text {th }}$ rank in $2010-11$ and 0.837 in 2011-12 with rank $2^{\text {nd }}$. Thus, from the point of view of health infrastructure beginning year 1991-92 was not so encouraging because of $19^{\text {th }}$ rank; but then conditions seemed to be improving in between with certain fluctuations and updowns. On the whole, health infrastructure index score is found to stood between 0 and 0.5 for eleven years; between 0.5 and 0.6 for two years; 0.6 and above for eight years.

Now, the findings are summarized with certain policy implications and future research directions in the next section.

\section{CONCLUSION AND POLICY IMPLICATIONS}

In nut shell, the present study is a humble attempt to examine the status of health infrastructure via constructing its index for State of Haryana. For which, firstly, the relevant indicators of health infrastructure are analyzed individually by their raw data as well as by computing descriptive statistics. The analysis reveals that health infrastructure' indicators namely numbers of PHCs, CHCs, SCs, doctors, ayurvedic and homoeopathic

Journal of Technology Management for Growing Economies, Volume 9, Number 1, April 2018
Construction

of Health

Infrastructure 
Goel, M. M.

Garg, I.

institutions and their dispensers/compounders have increased as their CAGR is positive. While, numbers of hospitals, dispensaries, nurses, other staff, beds, unani institutions and vaidyas/hakims have experienced negative CAGR. Besides, CHCs have achieved highest rate of growth in their number but also possess much dispersions. Meanwhile, numbers of PHCs, CHCs, SCs, and homoeopathic institutions are at their maximum number in 2011-12 (latest year of data) whereas dispensaries and unani institutions are found to experience their minimum number for the same year.

Next, summated index of all indicators of health infrastructure is prepared by applying principal component analysis (PCA) in various steps while explaining its detailed methodology. First of all, available data is normalized on which PCA is applied; consequently correlation matrix, KMO measure and Bartlett's test result are attempted which are found to favor the application of PCA. Secondly, three principal or latent components capable of representing all original variables are identified on the basis of their eigenvalues produced by PCA. Next, final output of PCA in terms of matrix of component loadings is attained to compute final weights for all variables (indicators of health infrastructure). By utilizing these weights, composite index of health infrastructure is constructed.

The scores of health infrastructure index reveal that 2004-05 is the best year for Haryana's health infrastructural status due to first rank. This rank is achieved in thirteenth year from 1991-92. Between 1991-92 and 2011-12, up and downs in index scores as well as in ranks are felt and thus continuous yearly improvement in ranks are not seen. On the whole, in health infrastructure index, Haryana State have experienced average and above score ( 0.6 and above) for eight years while for eleven years the score remained 0.5 and lesser, among time period of twenty one years. However, a very embarrassing situation is found during 200910 with lowest rank for which health infrastructure index scores zero implying the least availability of health infrastructural facilities for that year in comparison with other years. Thus, one cannot deny the fact that variations exist in the availability of overall health facilities over the years in the State of Haryana. Since, the State have attained second rank in health infrastructure index during the year 2011-12, therefore, there is a hope for further promotion of the status of health infrastructural facilities in coming years.

The present research implicated that the status of health infrastructure needs to be improved in the State of Haryana. The negative growth rate 
of certain indicators of health infrastructure is a serious cause of concern which require immediate attention from Government. Moreover, less than average score of health infrastructure index for many years also highlights the poor status of health infrastructure in the State. It may be due to lack of adequate investments in health infrastructure. Thus, there is emergence for sufficient amounts of public expenditure that must be incurred on health infrastructure. Besides, growing demand for healthcare services calls for enhancement in budgetary allocations on health sector every year. However, economically backward sections of society prominently depend on the public sector health care facilities; therefore, it becomes the primary duty of the State to ensure accessibility and affordability of health services to all citizens in general and vulnerable sections in particular. Last but not least, to develop health sector according to modern world, the corrupt practices among health service providers and financial leakages by Government officials must also be checked via adopting good governance at all levels.

\section{LIMITATIONS AND FUTURE RESEARCH DIRECTIONS}

Generally, researchers face certain problems while conducting their research which are called the limitations of their study. In the present context, first limitation is that some important indicators of health infrastructure including number of ambulances, blood banks, and stock of medicines, are not undertaken due to the unavailability of their data. Secondly, health infrastructure index is constructed by employing an econometric technique namely Principal Component Analysis which itself has certain shortcomings including requirement of large number of variables or indicators, adequate sample size and variables must be correlated (at least moderately) with each other.

With regard to future research directions, the present study will be directive for future researches as it explains construction of health infrastructure index in step by step procedure. Besides, the present research can be extended by including data for more years and more indicators. Furthermore, the index for health outcomes by taking data on its indicators can also be constructed for the state of Haryana.

\section{REFERENCES}

Abdi, H., \& Williams, L. J. (2010). Principal component analysis. WIREs Computational Statistics, 2(4), 433-459.

Anand, M. (2014). Health status and health care services in Uttar Pradesh and Bihar: A comparative study. Indian Journal of Public Health, 58(3), 174-179.

Constantin, C. (2014). Principal component analysis - A powerful tool in computing marketing information. Bulletin of the Transilvania University of Braşov, 7 (56), 25-30.

Journal of Technology Management for Growing Economies, Volume 9, Number 1, April 2018
Construction

of Health

Infrastructure 


\section{Goel, M. M. Garg, I.}

Daka, L., \& Fandamu, H. (2016). Evaluating poverty determinants in Zambia with principle component analysis and logistic regression. International Journal of Multidisciplinary Research and Development, 3(2), 320-327.

Debapriya, A., \& Mohanty, M. K. (2008). Inter-District disparity in the levels of development in education and health care facilities - A case of Orissa. Indian Journal of Regional Science, 40(1), 118-123.

Fernando, M.A.C.S.S., Samita, S., \& Abeynayake, R. (2012). Modified factor analysis to construct composite indices: Illustration on urbanization index. Tropical Agricultural Research, 23(4), 327-337.

Goel, M.M. (2011). Economics of human resource development in India. New Delhi: VK Global Publications.

Goel, M.M., \& Garg, I. (2016). Public expenditure on health and its impact on health infrastructure and health status in Haryana. Voice of Research, 5(2), 9-18.

Hair, Jr Joseph F., Anderson, R. E., Tatham, Ronald L., \& Black, William C. (2006). Multivariate data analysis ( $5^{\text {th }}$ ed.). New Delhi: Dorling Kindersley (India) Pvt. Ltd, Pearson Education, Inc.

Hoque, Sonia Ferdous (2014). Asset-based poverty analysis in rural Bangladesh: A comparison of principal component analysis and fuzzy set theory (Working Paper No. 59). Retrieved from Sustainability Research Institute (SRI), University of Leeds, United Kingdom website:

https://www.see.leeds.ac.uk/fileadmin/Documents/research/sri/workingpapers/SRIPs-59.pdf

IZUMI Foundation (2013). Health care infrastructure. Retrieved from http://izumi.org/about/ how-we-work/health-care-infrastructure/

Kumar, A., \& Gupta, S. (2012). Health infrastructure in India: Critical analysis of policy gaps in the Indian healthcare delivery. Retrieved from Vivekananda International Foundation website: http://www.vifindia.org/sites/default/files/health-infrastructure-in-india-critical-analysis-of-policy-gaps-in-the-indian-healthcare-delivery.pdf

Kumari, R., \& Raman, R. (2011). Inter-District disparity in health care facility and education: A case of Uttar Pradesh. Journal of Education and Practice, 2(1), 38-56.

Lyngdoh, Lasara M. (2015). Inter-State variations in rural healthcare infrastructure in NorthEast India. The NEHU Journal, 13(2), 31-48.

Mooi, E., \& Sarstedt, M. (2011). A concise guide to market research: The process, data, and methods using IBM SPSS statistics. Heidelberg: Springer.

Nicoletti, G., Scarpetta, S., \& Boylaud, O. (2000). Summary indicators of product market regulation with and extension to employment protection legislation (Working Paper No. 226). Retrieved from OECD, Economics Department website: https://www.oecd.org/eco/outlook/1880867.pdf ]

OECD (2008). Handbook on constructing composite indicators: Methodology and user guide. Retrieved from https://www.oecd.org/std/42495745.pdf

Saikia, H. (2012). Regional inequality of social sector development in India. Romanian Journal of Social Science, 6(2), 73-90.

Saikia, H., \& Bhattacharjee, D. (2011). Quantifying basic health care facilities in Assam: where do the districts stand? Elixir Soc. Sci., 36(2011), 3476-3482.

Singh, N., \& Gupta, K. (2013). Environmental attitude and ecological behaviour of Indian consumers. Social Responsibility Journal, 9(1), 4-18.

Subba Lakshmi, T., \& Sahoo, Dukhabandhu (2013). Health infrastructure and health indicators: The case of Andhra Pradesh, India. IOSR Journal of Humanities and Social Science, 6(6), 22-29.

Samanta, Rajeeb (2015). Block level disparity in social development: A case study of Paschim Medinipur, West Bengal, India. International Journal of Scientific Engineering and Research, 3(4), 92-95.

Journal of Technology Management for Growing Economies, Volume 9, Number 1, April 2018 
Sepehrdoust, Hamid (2009). Health care analysis and regional disparities in different provinces of Iran. Iranian Economic Review, 14(24), 113-134.

Sharpe, A., \& Andrews, B. (2012). An assessment of weighting methodologies for composite indicators: The case of the index of economic well-being (CSLS Research Report No. 201210). Retrieved from CSLS, Ontario website: http://www.csls.ca/reports/csls2012-10.pdf

Singh, A.K., \& Kumra, V.K. (2016). Analysis of micro level disparities in healthcare infrastructure in Allahabad District, Uttar Pradesh, India. The Journal of Bengal Geographer, 5(4), 37-50

Economic and Statistical Advisor, Planning Department, Government of Haryana. (1997). Statistical abstract Haryana: 1995-96.

(1999) Statistical abstract Haryana: 1997-98.

(2002) Statistical abstract Haryana: 2000-01.

(2004) Statistical abstract Haryana: 2002-03.

(2007) Statistical abstract Haryana: 2005-06.

Department of Economic and Statistical Analysis, Haryana. (2009) Statistical abstract Haryana: 2007-08.

(2012) Statistical abstract Haryana: 2010-11.

(2014) Statistical abstract Haryana: 2012-13.

(2015) Statistical abstract Haryana: 2013-14.

(2016) Statistical abstract of Haryana: 2014-15.
Construction

of Health

Infrastructure 